\title{
Corrigendum to "Effect of Narrow-Band Ultraviolet B Phototherapy and Methotrexate on MicroRNA (146a) Levels in Blood of Psoriatic Patients"
}

\author{
Amal Abou El-Fadle, ${ }^{1}$ Asmaa M. Ele-Refaei, ${ }^{2}$ and Fatma M. El-Esawy ${ }^{2}$ \\ ${ }^{1}$ Medical Biochemistry Department, Faculty of Medicine, Benha University, Benha, Egypt \\ ${ }^{2}$ Dermatology \& Andrology Department, Faculty of Medicine, Benha University, Benha, Egypt \\ Correspondence should be addressed to Fatma M. El-Esawy; fatmaelesawy99@yahoo.com \\ Received 20 January 2016; Accepted 16 June 2016 \\ Copyright (C) 2016 Amal Abou El-Fadle et al. This is an open access article distributed under the Creative Commons Attribution \\ License, which permits unrestricted use, distribution, and reproduction in any medium, provided the original work is properly \\ cited.
}

In the article titled "Effect of Narrow-Band Ultraviolet B Phototherapy and Methotrexate on MicroRNA (146a) Levels in Blood of Psoriatic Patients," [1] Dr. Amal Abou El-Fadle was missing from the author list. The corrected author list is shown above. The "Acknowledgments" section was missing, and should be added as follows.

\section{Acknowledgments}

We thank Naglaa Azab of the Medical Biochemistry Department for assistance with the molecular biology investigations.

\section{References}

[1] A. M. Ele-Refaei and F. M. El-Esawy, "Effect of narrow-band ultraviolet B phototherapy and methotrexate on MicroRNA (146a) levels in blood of psoriatic patients," Dermatology Research and Practice, vol. 2015, Article ID 145769, 5 pages, 2015. 


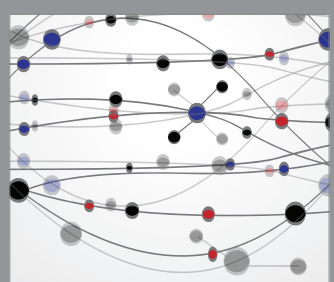

The Scientific World Journal
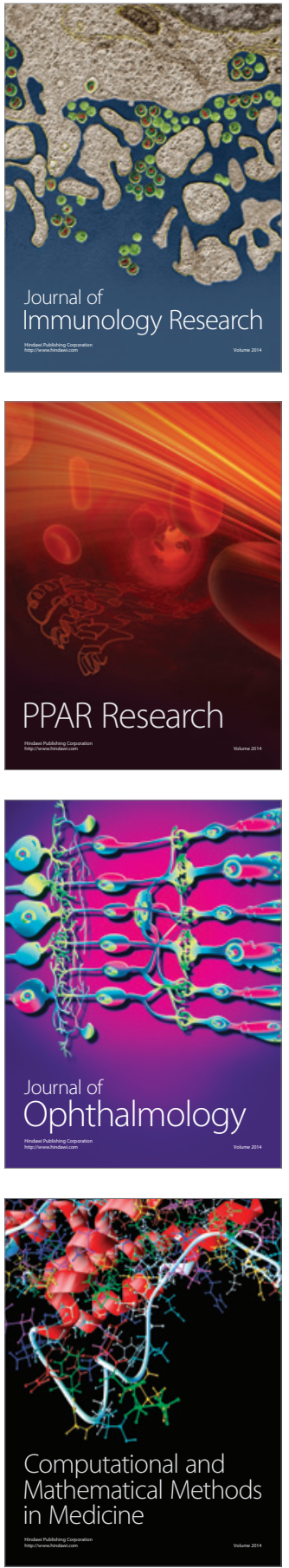

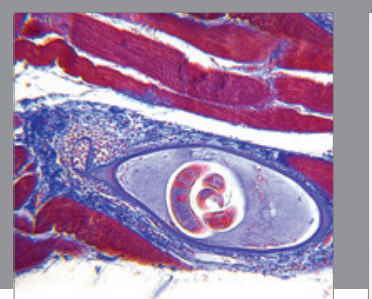

Gastroenterology Research and Practice

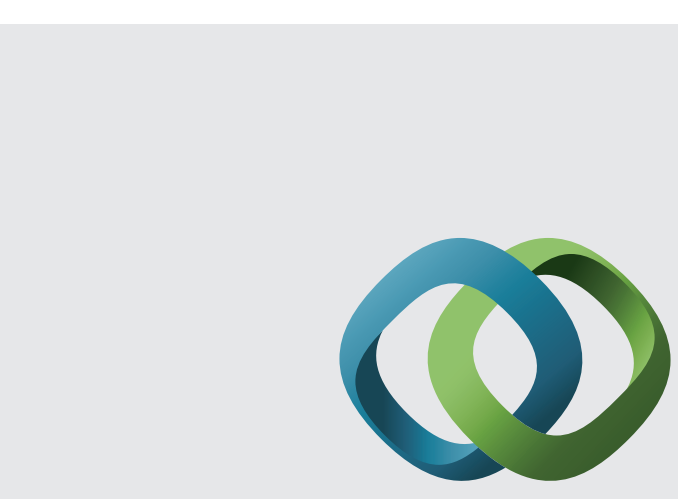

\section{Hindawi}

Submit your manuscripts at

http://www.hindawi.com
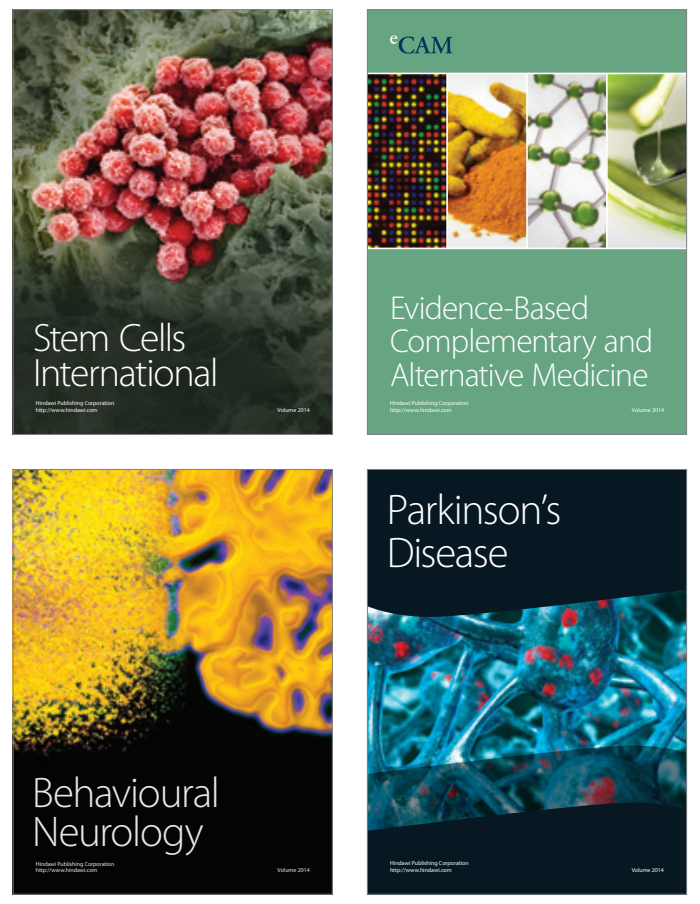
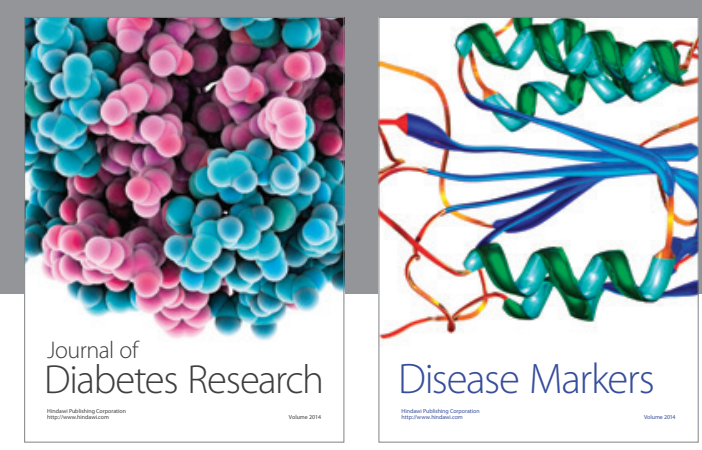

Disease Markers
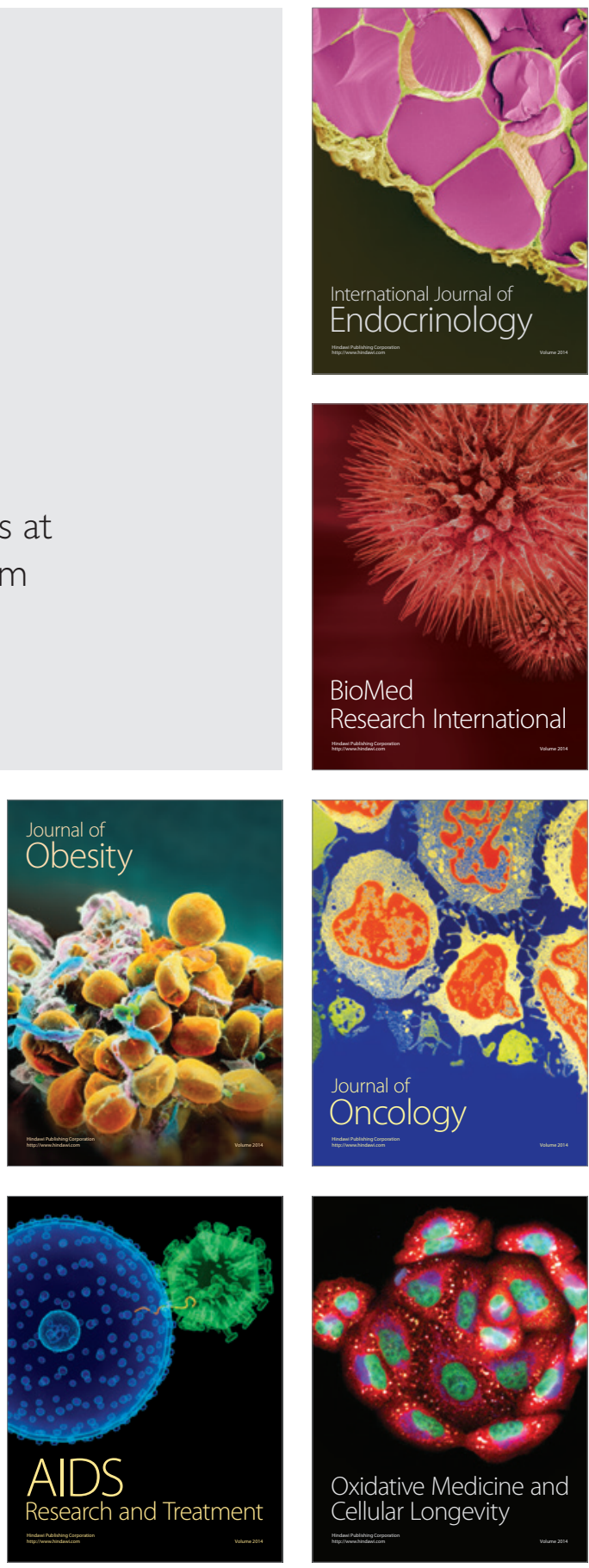